\title{
Article
}

\section{Inflammatory Markers and Thromboembolic Risk in Patients with Non-Muscle-Invasive Bladder Cancer}

\author{
Daniel Balan ${ }^{1}$ (D), Mihai Dorin Vartolomei ${ }^{2}$, Annamária Magdás ${ }^{3, *}$, Noemi Balan-Bernstein ${ }^{4}$, \\ Septimiu Toader Voidăzan ${ }^{5}$ and Orsolya Mártha ${ }^{1}$
}

1 Department of Urology, University of Medicine, Pharmacy, Science and Technology “G.E.Palade" of Targu-Mures, 540142 Targu-Mures, Romania; balan_dani@yahoo.com (D.B.); orsim@hotmail.com (O.M.)

2 Urology Department, Vienna General Hospital, 1090 Vienna, Austria; mdvartolomei@yahoo.com

3 Department of Internal Medicine, University of Medicine, Pharmacy, Science and Technology "G.E.Palade” of Targu-Mures, 540142 Targu-Mures, Romania

4 Clinic of Pneumology, Mures County Hospital, 540103 Targu-Mures, Romania; b.noemi47@gmail.com

5 Department of Epidemiology, “G. E. Palade” University of Medicine, Pharmacy, Science, and Technology of Targu Mures, 540142 Targu-Mures, Romania; septimiu.voidazan@umfst.ro

* Correspondence: anamaria.magdas@umfst.ro

Citation: Balan, D.; Vartolomei, M.D.; Magdás, A.; Balan-Bernstein, N.; Voidăzan, S.T.; Mártha, O Inflammatory Markers and Thromboembolic Risk in Patients with Non-Muscle-Invasive Bladder Cancer. J. Clin. Med. 2021, 10, 5270. https://doi.org/10.3390/jcm10225270

Academic Editor: Petros Grivas

Received: 26 September 2021 Accepted: 9 November 2021 Published: 12 November 2021

Publisher's Note: MDPI stays neutral with regard to jurisdictional claims in published maps and institutional affiliations.

Copyright: (c) 2021 by the authors. Licensee MDPI, Basel, Switzerland. This article is an open access article distributed under the terms and conditions of the Creative Commons Attribution (CC BY) license (https:/ / creativecommons.org/licenses/by/ $4.0 /)$.

\begin{abstract}
Introduction: Patients with bladder cancer have a high risk of venous thrombosis that represents a key challenge for physicians in the decision-making for initiating anticoagulation therapy. Non-muscle-invasive bladder cancer (NMIBC) represents more than $70 \%$ of all diagnosed bladder malignancies; therefore, we aimed to evaluate the relationship of the neutrophil to lymphocyte ratio (NLR), lymphocyte to monocyte ratio (LMR), and risk of thrombosis by using the International Medical Prevention Registry on Venous Thromboembolism (IMPROVE) score as well as the risk of bleeding by using the IMPROVE Bleeding Risk Assessment Score in a study cohort. Material and Methods: This was a retrospective observational study involving 130 patients who met the inclusion criteria: age $>18$ years, stage pTa-pT1 NMIBC. The exclusion criteria were age < 18 years; stage pT2 or higher; or a presentation of metastasis, inflammatory, liver or autoimmune diseases, or other systemic neoplasms. In order to evaluate the risk of thromboembolic events as well as those of bleeding, the IMPROVE scores were calculated for each patient. Subjects were categorized in a Low IMPROVE group (<4 points) or a High IMPROVE group. By using uni- and multivariate regression models, we analyzed $C B C$-derived parameters which could be associated with a higher risk of venous thrombosis in subjects with low or high IMPROVE scores. Results: Patients with IMPROVE score greater than 4 were associated with higher NLR, LMR and lymphocyte values $(p<0.05)$. In a multivariate regression model, the IMPROVE score was significantly influenced by lymphocyte count $(p=0.007)$ as well as the NLR value $(p<0.0001)$. Conclusions: In our study population, subjects with NMIBC with low lymphocytes and NLR $>3$ were at a higher risk of developing venous thromboembolic events, reflected by an IMPROVE score of greater than 4 . The IMPROVE and IMPROVE Bleeding Risk Assessment Scores are easy to use, and, complemented with the CBC-derived lymphocyte to monocyte ratio as a prothrombotic marker, could aid in the decision of prophylactic anticoagulation therapy during admission.
\end{abstract}

Keywords: IMPROVE; neutrophil to lymphocyte ratio; complete blood count; lymphocyte to monocyte ratio

\section{Introduction}

It is well known that patients with malignancies have a high risk of venous thrombosis. However, the risks of thrombosis and those of bleeding often coexist, and represent the main challenge for physicians in decision making for the use of anticoagulation therapy. Complete blood counts (CBCs) are a routinely used laboratory test, and the distribution of leukocyte types such as the neutrophil to lymphocyte ratio (NLR) as a prognostic 
inflammatory marker in vascular diseases or the lymphocyte to monocyte ratio (LMR) as a marker of outcome in malignancies has gained attention [1-4].

In addition, several scores have been used to evaluate cancer patients at high risk for thromboembolic events, although inflammation may play an additional role in this direction. Nevertheless, bleeding risk should also guide clinical decision-making and is of high importance in patients before starting oncological treatment. A few clinical studies have evaluated the association of non-specific inflammatory markers-NLR, platelet to lymphocyte ratio (PLR), or lymphocyte to monocyte ratio (LMR)—and risk of bleeding [5,6].

The IMPROVE score is a validated tool for assessing patients for the three-month risk of thrombosis, although the IMPROVE Bleeding score is lacking researchers' attention $[7,8]$. The prognostic role of NLR in tumor progression and disease recurrence has been highlighted in previous studies, but to the best of our knowledge in cancer patients, few have investigated the association of non-specific pro-inflammatory markers derived from $C B C$ and bleeding risk $[9,10]$. Therefore, we aimed to evaluate the relationship of NLR, LMR, and the risk of thrombosis by using the IMPROVE score as well as the risk of bleeding using the IMPROVE Bleeding Risk Assessment Score in patients with non-muscle-invasive bladder tumors.

\section{Material and Methods}

We performed a retrospective observational study at the County Clinical Hospital, Department of Urology in Targu Mures, analyzing NMIBC patients between January 2016 and December 2020. The study was conducted in accordance with the World Medical Association Declaration of Helsinki and was approved by the Ethical Committee of the Mures County Hospital (Opinion form Nr 9572). A total of 130 patients with non-muscleinvasive bladder cancer were included in this survey who met the inclusion criteria: age $>18$ years, stage pTa-pT1 NMIBC. Exclusion criteria were the following: age $<18$ years, stage pT2 or higher, and presentation of metastasis, inflammatory, liver or autoimmune diseases, or other systemic neoplasms. In order to evaluate the risk of thromboembolic events as well as those of bleeding, the IMPROVE and IMPROVE Bleeding Risk Assessment Scores were calculated for each patient by using the calculators available online. Tumor staging was established before inclusion in the study. We noted the grade, stage and size of the tumor. Based on the cut-off value of 4 points for the IMPROVE score (modified IMPROVE-Spyropoulos), subjects scoring $<4$ points were categorized into the Low IMPROVE group, whereas those who scored $\geq 4$ points were in the High IMPROVE group.

Anthropometric, clinical, and biological data were recorded for each patient. Blood samples were collected in the morning between 8 and $10 \mathrm{AM}$ from the brachial vein after at least $8 \mathrm{~h}$ of fasting. As part of a routine laboratory test, a complete blood count was analyzed at a maximum of 7 days prior to surgical intervention. To assess the inflammatory status of the patients, neutrophils, lymphocytes, monocytes, neutrophil to lymphocyte ratios, and lymphocyte to monocyte ratios were calculated. NLR $>3$ was considered as a negative prognostic marker in NMIBC; therefore, we also evaluated IMPROVE and IMPROVE Bleeding scores among subjects with low NLR values $<3$ and high NLR values $\geq 3$.

Statistical Analyses

The statistical analysis was performed using the IBM SPSS Statistics 22 program (IBM Corporation, Armonk, NY, USA), involving descriptive and interferential statistics. Quantitative variables were tested by using the Kolmogorov-Smirnov test, and are expressed as median values, and between-group comparisons were performed using the Student's $t$-test or the Mann-Whitney $U$ test. Categorical variables were displayed as frequencies, $n(\%)$, and comparisons between the groups were assessed with the chi-squared test. We also analyzed the correlation between the variables by using Spearman's test. Variables included in the multivariate analysis were selected on the basis of the best results of bivariate analyses (at a significance level of $p<0.05$ ). Univariate and multivariate regression of predictive factors was conducted using the IMPROVE score as a dependent variable and age, lymphocytes, NLR ( $>3)$, monocytes, lymphocyte to monocyte ratio, tumor size $>3 \mathrm{~cm}$ 
and previous VTE as independent predictive variables. Statistical significance was set at $p<0.05$.

\section{Results}

Among 130 (100\%) subjects included in the study, the Low IMPROVE group included 66 patients, whereas in the High IMPROVE group there were 64 patients. Characteristics of the groups, as well as laboratory data and tumor grading, are presented in Table 1.

Table 1. Demographic and laboratory data of the study groups.

\begin{tabular}{|c|c|c|c|}
\hline Characteristics & $\begin{array}{c}\text { Low IMPROVE Group } \\
<4 \text { Points } \\
(n=66)\end{array}$ & $\begin{array}{l}\text { High IMPROVE Group } \\
\geq 4 \text { Points } \\
(n=64)\end{array}$ & $p$-Value \\
\hline Age (years) mean $\pm \mathrm{SD}$ & $65.77 \pm 11.316$ & $73.64 \pm 9.03$ & $<0.0001$ \\
\hline Gender, M/F nr (\%) & $55 / 11(16.9 \%)$ & $54 / 10(15.6 \%)$ & 0.84 \\
\hline $\begin{array}{l}\text { Lymphocytes, } 10^{3} / \mu \mathrm{L} \\
\text { median (min-max) } \\
\text { and mean } \pm \mathrm{SD}\end{array}$ & $\begin{array}{l}2.00(0.00-4.00) \\
2.04 \pm 0.89\end{array}$ & $\begin{array}{l}2.00(0.00-4.00) \\
1.65 \pm 0.83\end{array}$ & 0.005 \\
\hline $\begin{array}{l}\text { Neutrophils, } 10^{3} / \mu \mathrm{L} \\
\text { median (min-max) }\end{array}$ & $6.14 \pm 2.88$ & $7.22 \pm 4.6$ & 0.21 \\
\hline $\begin{array}{l}\text { Neutrophil to lymphocyte ratio } \\
\text { median (min-max) }\end{array}$ & $2.44(1.15-19.68)$ & $3.50(1.05-63.47)$ & 0.002 \\
\hline NLR > 3, nr $(\%)$ & $26(40.0 \%)$ & $41(64.1 \%)$ & 0.008 \\
\hline $\begin{array}{l}\text { Monocytes, } 10^{3} / \mu \mathrm{L} \\
\text { median (min-max) }\end{array}$ & $1.00(0.00-1.00)$ & $0.00-2.00$ & 0.046 \\
\hline $\begin{array}{l}\text { Lymphocyte to monocyte ratio } \\
\text { median (min-max) }\end{array}$ & $3.75(0.557-12.42)$ & $2.69(0.32-8.31)$ & 0.0001 \\
\hline Previous VTE, nr (\%) & $2(5.0 \%)$ & $18(28.1 \%)$ & 0.004 \\
\hline $\begin{array}{l}\text { Tumor stage } \\
\mathrm{pT} 1, \mathrm{nr}(\%)\end{array}$ & $20(30.8 \%)$ & $24(37.5 \%)$ & \multirow{5}{*}{0.28} \\
\hline pT1 + CIS & $0(0.0 \%)$ & $1(1.6 \%)$ & \\
\hline pT1a & $0(0.0 \%)$ & $1(1.6 \%)$ & \\
\hline $\mathrm{pTa}$ & $43(66.2 \%)$ & $38(59.4 \%)$ & \\
\hline $\mathrm{pTa}+\mathrm{CIS}$ & $2(3.1 \%)$ & $0(0.0 \%)$ & \\
\hline $\begin{array}{l}\text { Tumor grade } \\
\text { G1 }\end{array}$ & $3(4.6 \%)$ & $1(1.6 \%)$ & \multirow{3}{*}{0.43} \\
\hline G2 & $34(52.3 \%)$ & $31(48.4 \%)$ & \\
\hline G3 & $23(35.4 \%)$ & $22(34.4 \%)$ & \\
\hline Tumor size $>3 \mathrm{~cm}, \mathrm{nr}(\%)$ & $44(67.7 \%)$ & $54(84.4 \%)$ & 0.047 \\
\hline
\end{tabular}

VTE-venous thromboembolism, CIS—cystectomy.

The distribution of the subjects based on gender was as follows: Twenty-one females and 109 males. Regarding the tumor stage, in females, 14 had stage pTa, whereas 7 had stage pT1. In males, 71 had stage pTa and 38 had stage pT1; this was not statistically significant, $p=0.89$. We noticed a statistically significant difference among males and females regarding the IMPROVE score, $3.95 \pm 0.11$ versus $2.9 \pm 0.27, p=0.006$. The IMPROVE Bleeding score was $9.69 \pm 0.21$ in males versus $8.69 \pm 0.61$ in females, $p=0.07$.

In a univariate logistic regression model (Table 2), the IMPROVE score was significantly influenced by the lymphocyte count ((OR: 0.12; CI95\%: 0.05-0.26, $p<0.0001)$, NLR ratio (OR: 0.37; CI95\%: 0.18-0.76, $p=0.007$ ), monocyte count (OR: 8.91; CI95\%: 1.99-39.76, $p=0.0042$ ) and lymphocyte to monocyte ratio (OR: 0.40; CI95\%: 0.29-0.56, $p=0.0001$ ). 
Table 2. Results from univariate logistic regression.

\begin{tabular}{cccc}
\hline Variables & Odds Ratio & $\mathbf{9 5 \%}$ CI & $p$ \\
\hline Age & 1.0200 & 0.9873 to 1.0538 & 0.2329 \\
\hline Lymphocytes & 0.1204 & 0.0546 to 0.2653 & $<0.0001$ \\
\hline NLR $(>3)$ & 0.3740 & 0.1834 to 0.7624 & 0.007 \\
\hline Monocytes & 8.9106 & 1.9967 to 39.7642 & 0.0042 \\
\hline Lymphocyte to monocyte Rratio & 0.4082 & 0.2925 to 0.5696 & 0.0001 \\
\hline Tumor size $>3$ cm & 1.3258 & 0.5480 to 3.2073 & 0.53 \\
\hline Previous VTE & 0.9091 & 0.3427 to 2.4114 & 0.84 \\
\hline
\end{tabular}

In the multivariate logistic regression model (Table 3), IMPROVE score is significantly influenced by the lymphocyte count and the neutrophil to lymphocyte ratio.

Table 3. The final multivariable logistic model.

\begin{tabular}{cccc}
\hline Variables & Odds Ratio & $\mathbf{9 5 \% C I}$ & $p$ \\
\hline Lymphocytes & 0.1214 & 0.0303 to 0.4864 & 0.0029 \\
NLR $(>3)$ & 0.4697 & 0.2170 to 0.9845 & 0.0098 \\
Monocytes & 12.8667 & 0.2403 to 688.8504 & 0.2084 \\
Lymphocyte to monocyte ratio & 0.8590 & 0.4312 to 1.7111 & 0.6655 \\
\hline
\end{tabular}

Between the variables of interest we applied Spearman type correlations, obtaining significant values, $p$ value below 0.05 (*. Correlation is significant at the 0.05 level (2-tailed)).

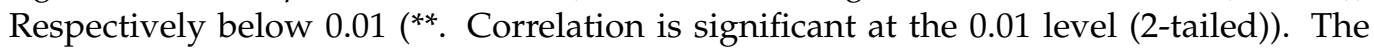
correlation coefficient $r$ (rho) is interpreted compared to the value 1 , at values below 1 we have negative correlations, at values above 1 there are positive correlations. The data are represented in Table 4.

Table 4. Spearmen's correlation for study population with IMPROVE score $\geq 4$ points.

\begin{tabular}{|c|c|c|c|c|c|c|c|c|}
\hline \multicolumn{9}{|c|}{ Correlations } \\
\hline & & & Age & Neutrophils & Lymphocytes & NLR & Monocytes & LMR \\
\hline \multirow{12}{*}{$\begin{array}{c}\text { Spearman's } \\
\text { rho }\end{array}$} & \multirow{2}{*}{ Age } & Correlation Coefficient & 1.000 & -0.070 & -0.196 & 0.110 & -0.009 & $-0.269 *$ \\
\hline & & Sig. (2-tailed) & . & 0.575 & 0.111 & 0.376 & 0.944 & 0.028 \\
\hline & \multirow{2}{*}{ Neutrophils } & Correlation Coefficient & -0.070 & 1.000 & 0.138 & $0.678^{* *}$ & 0.159 & $-0.254 *$ \\
\hline & & Sig. (2-tailed) & 0.575 & . & 0.266 & 0.000 & 0.198 & 0.038 \\
\hline & \multirow{2}{*}{ Lymphocytes } & Correlation Coefficient & -0.196 & 0.138 & 1.000 & $-0.489^{* *}$ & $0.307 *$ & $0.466^{* *}$ \\
\hline & & Sig. (2-tailed) & 0.111 & 0.266 & . & 0.000 & 0.012 & 0.000 \\
\hline & \multirow[b]{2}{*}{ NLR } & Correlation Coefficient & 0.110 & $0.678 * *$ & $-0.489 * *$ & 1.000 & -0.023 & $-0.613^{* *}$ \\
\hline & & Sig. (2-tailed) & 0.376 & 0.000 & 0.000 & . & 0.851 & 0.000 \\
\hline & \multirow{2}{*}{ Monocytes } & Correlation Coefficient & -0.009 & 0.159 & $0.307 *$ & -0.023 & 1.000 & $-0.408^{* *}$ \\
\hline & & Sig. (2-tailed) & 0.944 & 0.198 & 0.012 & 0.851 & . & 0.001 \\
\hline & \multirow{2}{*}{ LMR } & Correlation Coefficient & $-0.269 *$ & $-0.254 *$ & $0.466 * *$ & $-0.613^{* *}$ & $-0.408^{* *}$ & 1.000 \\
\hline & & Sig. (2-tailed) & 0.028 & 0.038 & 0.000 & 0.000 & 0.001 & . \\
\hline
\end{tabular}

${ }^{*}$ Correlation is significant at the 0.05 level (2-tailed). ${ }^{* *}$ Correlation is significant at the 0.01 level (2-tailed).

\section{Discussions}

In this study, we investigated the relationship between $\mathrm{CBC}$-derived parameters such as NLR, LMR and the risk of thrombosis, as well as those of bleeding in patients with non-muscle-invasive bladder cancer hospitalized for surgical intervention. The incidence of venous thromboembolic events is much higher in patients with bladder cancer compared to other malignancies; thus, we considered it of high importance to investigate this popula- 
tion [11]. The non-muscle-invasive type represents more than $70 \%$ of diagnosed bladder cancers; therefore, it was well-founded to investigate thromboembolic and bleeding risks in this cohort [12].

Although the IMPROVE score is used in patients in order to evaluate the three-month risk of venous thromboembolic events, patients with bladder cancer admitted to the hospital for various medical or non-medical conditions often present several coagulationrelated problems which have to be solved by a multidisciplinary team [13-15].

Our results revealed that patients with higher IMPROVE risk scores are associated with older age, higher NLR and monocyte values, as well as lower LMR values. Among these subjects, a history of deep vein thrombosis was recorded in $28 \%$ compared to $5 \%$ in the Low IMPROVE group, and anticoagulation therapy during admission was required in $78.12 \%$. However, subjects with NLR values greater than 3 are at high risk for the progression and recurrence of cancer; therefore, we thought it would be meaningful to assess both the thromboembolic as well as the bleeding risk. We noticed greater values for IMPROVE and IMPROVE Bleeding scores; however, we could not demonstrate statistically significant correlations between clotting disorders and NLR values. These results are in accordance with some data available in this research field [1]. Despite these results, the NLR has been already validated as a prognostic marker in the recurrence and progression of bladder tumors, although there is a need for further research to identify other CBC-derived parameters as risk factors for thromboembolic events [16].

Another study performed on subjects admitted for pulmonary embolism revealed that increased levels of NLR and LMR were associated with increased mortality risk in patients with moderately low and low risk of PE [17]. In cardiovascular as well as in oncological diseases, some non-specific inflammatory biomarkers-NLR and LMR - have gained attention due to their power in predicting the occurrence of cancer-related deep vein thrombosis [1,18-20]. Although the cut-off value for LMR differs in each study, its role as a prognostic factor in cancer, including bladder cancer, has been well established [21-24]. Thus far, studies have revealed that the imbalance between lymphocytes and monocytes worsens the inflammatory status of the patient, which will lead to thrombosis. However, there is no clear cut-off value defined for LMR; in a retrospective study, Zhu et al. found that LMR has the power to predict the risk of deep vein thrombosis in patients after total joint arthroplasty. The cut-off value was based on an assessment of the area under the curve [5]. Li et al. found that low LMR was linked to poor outcomes in patients with cerebral venous sinus thrombosis, which could be the result of monocyte deactivation [25].

In our study, in uni- and multivariate regression models, we demonstrated that the IMPROVE score is significantly influenced by the lymphocyte count as well as high NLR values. Since, lymphocyte count does not show Gaussian distribution, it has been displayed as minimum to maximum, but the same parameter assessed as mean $\pm \mathrm{SD}$ the difference is statistically significant, $2.04 \pm 0.89$ versus $1.65 \pm 0.83 \times 10^{3} / \mu \mathrm{L}(p<0.005)$ in the high IMPROVE group. To the actual state of knowledge, lymphocyte count alone does not have the power to be an independent prognostic factor for venous thromboembolism; however, as part of the neutrophil to lymphocyte ratio is has been proved to be an inflammatory marker of tumor progression and thus of thrombosis.

In a comprehensive study, Braun A. et.al. stated that platelets play a critical role in thrombosis, hemostasis and the arrest of bleeding in healthy conditions [26], and thrombotic events have frequently been observed in cancer patients, indicating an active involvement of platelets and factors released from platelets in tumor progression, enhancing pro-coagulant activity and blood clotting $[27,28]$. Although the systemic effects of platelets in thrombotic complications of cancer patients have been described, compelling experimental and clinical evidence have linked platelet function to tumor angiogenesis, tumor progression and metastasis through the interaction of platelets with cancer cells and the tumor microenvironment [26].

Ho-Tin-Hoé B. et.al. published an article presenting that platelets support the recruitment of leukocytes to sites of inflammation and that platelets not only serve in concert 
as building blocks of the hemostatic plug, but also act individually as gatekeepers of the vascular wall to help preserve vascular integrity while coordinating the host defense, introducing the notion of "inflammation-associated hemostasis" [29].

The presence of cancer and lack of physical activity for at least three days as promoting factors for deep vein thrombosis can be found in several scores assessing the risk of deep vein thrombosis in hospitalized patients $[30,31]$. In cancer patients, inflammatory markers have been implemented in the guiding of specific therapy; thus, the same markers could be of high importance to also assess the risk of thrombosis. Therefore, the role of LMR as a new thrombo-inflammatory marker has been established in earlier studies, and seems to predict future thrombosis [25]. These findings were also supported by our study, where patients with a high risk of thrombosis, defined by an IMPROVE score greater than 4, were associated with lower values of LMR. By analyzing the characteristics of the study group based on gender, we noticed that only $16.3 \%$ were females. Nevertheless, the incidence of tumor stage was almost the same: $66.66 \%$ pTa in females versus $65.13 \%$ in males. The small number of females participating in this survey could also explain the lower scores of IMPROVE and the IMPROVE Bleeding scores. However, a statistically significant difference was recorded only in the case of the IMPROVE score.

The COVID-19 pandemic has represented an unprecedented challenge to every health system, putting an extra burden on the management of neoplasms. Matteo F. et al., in a multi-institutional retrospective cohort analysis on 2591 patients, stated that delays in treatment schedules and disease management were observed, and investigation of the oncological impacts of those differences should be advocated [32].

The study has several limitations. Firstly, the lack of data regarding D-dimers could have increased the statistical significance of the IMPROVE score and other proinflammatory markers. Other prothrombotic factors such as body mass index or tobacco use are also lacking in data, although we aimed to only focus on CBC-derived markers with a potential role in predicting venous thromboembolic events. Secondly, we did not include a control group consisting of patients with acute thrombosis or healthy individuals without cancer. The distribution of genders was not equal, because in our database, the male gender was more represented. We found that patients in the High IMPROVE group associated lower lymphocyte count which was also stipulated to influence the IMPROVE score in the univariate logistic regression model. However, we cannot state yet that lymphocyte count alone is a prothrombotic marker, only if integrated in the formula of other CBC-derived parameters. We think that future researches should implement other markers of venous thromboembolism like D-dimers or specific tumor markers in order to increase statistical significance of these data.

\section{Conclusions}

In our study, we found that subjects with NMIBC who associated low lymphocyte count, an NLR greater than 3, and a low lymphocyte to monocyte ratio were at higher risk of developing venous thromboembolic events, as reflected by an IMPROVE score greater than 4. The CBC-derived lymphocyte count, and neutrophil to lymphocyte ratio, are low-cost prothrombotic markers, useful in daily clinical practice in order to identify patients with cancer at high risk of developing venous thromboembolism in the perioperative period.

The IMPROVE and the IMPROVE Bleeding Risk Assessment Scores are easy to use, and if completed by the $\mathrm{CBC}$-derived neutrophil to lymphocyte ratio and lymphocyte to monocyte ratio, could be of practical relevance in the decision of starting prophylactic anticoagulation therapy during hospital admission.

Author Contributions: Conceptualization: D.B. and A.M.; methodology: N.B.-B.; software: S.T.V.; validation: M.D.V.; formal analysis: D.B. and A.M.; investigation: D.B., A.M. and N.B.-B.; resources: O.M.; data curation: D.B. and N.B.-B.; writing-original draft: D.B. and A.M.; writing-review and editing: S.T.V.; visualization: M.D.V.; supervision: O.M.; project administration: O.M. All authors have read and agreed to the published version of the manuscript. 
Funding: This research received no external funding.

Institutional Review Board Statement: The study was conducted in accordance with the World Medical Association Declaration of Helsinki and was approved by the Ethical Committee of the Mures County Hospital (Opinion form Nr 9572).

Informed Consent Statement: Informed consent was obtained from all subjects involved in the study.

Data Availability Statement: Data sharing not applicable.

Conflicts of Interest: The authors declare no conflict of interest.

\section{References}

1. Artoni, A.; Abbattista, M.; Bucciarelli, P.; Gianniello, F.; Scalambrino, E.; Pappalardo, E.; Peyvandi, F.; Martinelli, I. Platelet to Lymphocyte Ratio and Neutrophil to Lymphocyte Ratio as Risk Factors for Venous Thrombosis. Clin. Appl. Thromb. 2018, 24, 808-814. [CrossRef] [PubMed]

2. Stefaniuk, P.; Szymczyk, A.; Podhorecka, M. The Neutrophil to Lymphocyte and Lymphocyte to Monocyte Ratios as New Prognostic Factors in Hematological Malignancies-A Narrative Review. Cancer Manag. Res. 2020, 12, 2961-2977. [CrossRef] [PubMed]

3. Templeton, A.J.; McNamara, M.G.; Šeruga, B.; Vera-Badillo, F.E.; Aneja, P.; Ocaña, A.; Leibowitz-Amit, R.; Sonpavde, G.; Knox, J.J.; Tran, B.; et al. Prognostic role of neutrophil-to-lymphocyte ratio in solid tumors: A systematic review and meta-analysis. J. Natl. Cancer Inst. 2014, 106, dju124. [CrossRef] [PubMed]

4. Li, J.; Cheng, Y.; Ji, Z. Prognostic value of pretreatment lymphocyte-to-monocyte ratio in patients with urologic tumors: A PRISMA-compliant meta-analysis. Medicine 2019, 98, e14091. [CrossRef]

5. Zhu, X.; Yao, Y.; Yao, C.; Jiang, Q. Predictive value of lymphocyte to monocyte ratio and monocyte to high-density lipoprotein ratio for acute deep vein thrombosis after total joint arthroplasty: A retrospective study. J. Orthop. Surg. Res. 2018, 13, 211. [CrossRef]

6. Saand, A.R.; Yu, F.; Chen, J.; Chou, S.H.-Y. Systemic inflammation in hemorrhagic strokes-A novel neurological sign and therapeutic target? J. Cereb. Blood Flow Metab. 2019, 39, 959-988. [CrossRef] [PubMed]

7. Hostler, D.C.; Marx, E.S.; Moores, L.K.; Petteys, S.K.; Hostler, J.M.; Mitchell, J.D.; Holley, P.R.; Collen, J.F.; Foster, B.E.; Holley, A.B. Validation of the International Medical Prevention Registry on Venous Thromboembolism Bleeding Risk Score. Chest 2016, 149, 372-379. [CrossRef]

8. Spyropoulos, A.C.; Lipardi, C.; Xu, J.; Peluso, C.; Spiro, T.E.; De Sanctis, Y.; Barnathan, E.S.; Raskob, G.E. Modified IMPROVE VTE Risk Score and Elevated D-Dimer Identify a High Venous Thromboembolism Risk in Acutely Ill Medical Population for Extended Thromboprophylaxis. TH Open 2020, 4, e59-e65. [CrossRef]

9. Vartolomei, M.D.; Porav-Hodade, D.; Ferro, M.; Mathieu, R.; Abufaraj, M.; Foerster, B.; Kimura, S.; Shariat, S.F. Prognostic role of pretreatment neutrophil-to-lymphocyte ratio (NLR) in patients with non-muscle-invasive bladder cancer (NMIBC): A systematic review and meta-analysis. Urol. Oncol. 2018, 36, 389-399. [CrossRef]

10. Mártha, O.; Balan, D.; Porav-Hodade, D.; Drágus, E.; Vartolomei, M.D.; Chibelean, C.B.; Borda, A.; Pytel, Á.; Vida, O.Á. The role of neutrophil to lymphocyte ratio in patients with pTa non-muscle invasive bladder cancer. Rev. Romana Med. Lab. 2020, 28, 29-38. [CrossRef]

11. Zareba, P.; Duivenvoorden, W.C.M.; Pinthus, J.H. Thromboembolism in Patients with Bladder Cancer: Incidence, Risk Factors and Prevention. Bladder Cancer 2018, 4, 139-147. [CrossRef] [PubMed]

12. D'Andrea, D.; Moschini, M.; Gust, K.; Abufaraj, M.; Özsoy, M.; Mathieu, R.; Soria, F.; Briganti, A.; Rouprêt, M.; Karakiewicz, P.I.; et al. Prognostic Role of Neutrophil-to-Lymphocyte Ratio in Primary Non-muscle-invasive Bladder Cancer. Clin. Genitourin. Cancer 2017, 15, e755-e764. [CrossRef] [PubMed]

13. Schünemann, H.J.; Cushman, M.; Burnett, A.E.; Kahn, S.R.; Beyer-Westendorf, J.; Spencer, F.A.; Rezende, S.M.; Zakai, N.A.; Bauer, K.A.; Dentali, F.; et al. American Society of Hematology 2018 guidelines for management of venous thromboembolism: Prophylaxis for hospitalized and nonhospitalized medical patients. Blood Adv. 2018, 2, 3198-3225. [CrossRef] [PubMed]

14. Zhai, Z.; Kan, Q.; Li, W.; Qin, X.; Qu, J.; Shi, Y.; Xu, R.; Xu, Y.; Zhang, Z.; Wang, C.; et al. VTE Risk Profiles and Prophylaxis in Medical and Surgical Inpatients: The Identification of Chinese Hospitalized Patients' Risk Profile for Venous Thromboembolism (DissolVE-2)-A Cross-sectional Study. Chest 2019, 155, 114-122. [CrossRef]

15. Greene, M.T.; Spyropoulos, A.C.; Chopra, V.; Grant, P.J.; Kaatz, S.; Bernstein, S.J.; Flanders, S.A. Validation of Risk Assessment Models of Venous Thromboembolism in Hospitalized Medical Patients. Am. J. Med. 2016, 129, 1001.e9-1001.e18. [CrossRef]

16. Viers, B.R.; Boorjian, S.A.; Frank, I.; Tarrell, R.F.; Thapa, P.; Karnes, R.J.; Thompson, R.H.; Tollefson, M.K. Pretreatment neutrophilto-lymphocyte ratio is associated with advanced pathologic tumor stage and increased cancer-specific mortality among patients with urothelial carcinoma of the bladder undergoing radical cystectomy. Eur. Urol. 2014, 66, 1157-1164. [CrossRef]

17. Köse, N.; Yıldırım, T.; Akın, F.; Yıldırım, S.E.; Altun, İ. Prognostic role of NLR, PLR, and LMR in patients with pulmonary embolism. Bosn. J. Basic Med. Sci. 2020, 20, 248-253. [CrossRef] 
18. Zhang, H.; Li, J.; Chen, X.; Wu, N.; Xie, W.; Tang, H.; Li, C.; Wu, L.; Xiang, Y.; Zhong, L.; et al. Association of Systemic Inflammation Score With Atrial Fibrillation: A Case-Control Study With Propensity Score Matching. Heart Lung Circ. 2018, 27, 489-496. [CrossRef]

19. Riva, N.; Donadini, M.P.; Ageno, W. Epidemiology and pathophysiology of venous thromboembolism: Similarities with atherothrombosis and the role of inflammation. Thromb. Haemost. 2015, 113, 1176-1183. [CrossRef]

20. Samad, F.; Ruf, W. Inflammation, obesity, and thrombosis. Blood 2013, 122, 3415-3422. [CrossRef]

21. Ma, J.-Y.; Hu, G.; Liu, Q. Prognostic Significance of the Lymphocyte-to-Monocyte Ratio in Bladder Cancer Undergoing Radical Cystectomy: A Meta-Analysis of 5638 Individuals. Dis. Markers 2019, 2019, 7593560. [CrossRef]

22. Lee, S.-M.; Russell, A.; Hellawell, G. Predictive value of pretreatment inflammation-based prognostic scores (neutrophil-tolymphocyte ratio, platelet-to-lymphocyte ratio, and lymphocyte-to-monocyte ratio) for invasive bladder carcinoma. Korean J. Urol. 2015, 56, 749-755. [CrossRef]

23. Yoshida, T.; Kinoshita, H.; Yoshida, K.; Mishima, T.; Yanishi, M.; Inui, H.; Komai, Y.; Sugi, M.; Inoue, T.; Murota, T.; et al. Prognostic impact of perioperative lymphocyte-monocyte ratio in patients with bladder cancer undergoing radical cystectomy. Tumour Biol. 2016, 37, 10067-10074. [CrossRef]

24. Wang, Q.H.; Ji, J.L.; Li, H.; He, P.L.; Song, L.X.; Zhao, Y.; Wang, H.Y.; Huang, T.; Sun, X.X.; Cao, Y.W.; et al. Preoperative Lymphocyte-to-monocyte Ratio Predicts Prognosis in Patients with Stage T1 Non-muscle Invasive Bladder Cancer. Zhongguo Yi Хиe Ke Хue Yuan Хue Bao 2019, 41, 622-629.

25. Li, S.; Liu, K.; Zhang, R.; Gao, Y.; Fang, H.; Liu, X.; Pei, L.; Chou, L.-Y.R.; Guan, S.; Guo, X.; et al. Lower lymphocyte to monocyte ratio is a potential predictor of poor outcome in patients with cerebral venous sinus thrombosis. Stroke Vasc. Neurol. 2018, 4 , 148-153. [CrossRef]

26. Braun, A.; Anders, H.-J.; Gudermann, T.; Mammadova-Bach, E. Platelet-Cancer Interplay: Molecular Mechanisms and New Therapeutic Avenues. Front. Oncol. 2021, 11, 665534. [CrossRef]

27. Fernandes, C.J.; Morinaga, L.T.K.; Alves, J.L.; Castro, M.A.; Calderaro, D.; Jardim, C.V.P.; Souza, R. Cancer-associated thrombosis: The when, how and why. Eur. Respir. Rev. 2019, 28, 180119. [CrossRef]

28. Mukai, M.; Oka, T. Mechanism and management of cancer-associated thrombosis. J. Cardiol. 2018, 72, 89-93. [CrossRef]

29. Ho-Tin-Noé, B.; Boulaftali, Y.; Camerer, E. Platelets and vascular integrity: How platelets prevent bleeding in inflammation. Blood 2018, 131, 277-288. [CrossRef]

30. Wells, P.S.; Owen, C.; Doucette, S.; Fergusson, D.; Tran, H. Does this patient have deep vein thrombosis? JAMA 2006, 295, 199-207. [CrossRef]

31. Spyropoulos, A.C.; Anderson, F.A.; FitzGerald, G.; Decousus, H.; Pini, M.; Chong, B.H.; Zotz, R.B.; Bergmann, J.-F.; Tapson, V.; Froehlich, J.B.; et al. Predictive and associative models to identify hospitalized medical patients at risk for VTE. Chest 2011, 140, 706-714. [CrossRef]

32. Ferro, M.; Del Giudice, F.; Carrieri, G.; Busetto, G.M.; Cormio, L.; Hurle, R.; Contieri, R.; Arcaniolo, D.; Sciarra, A.; Maggi, M.; et al. The Impact of SARS-CoV-2 Pandemic on Time to Primary, Secondary Resection and Adjuvant Intravesical Therapy in Patients with High-Risk Non-Muscle Invasive Bladder Cancer: A Retrospective Multi-Institutional Cohort Analysis. Cancers 2021, 13, 5276. [CrossRef] 